\title{
Screening and evaluation of reliable traits of upland cotton (Gossypium hirsutum L.) genotypes for salt tolerance at the seedling growth stage
}

SIKDER Ripon Kumar, WANG Xiangru, JIN Dingsha, ZHANG Hengheng, GUI Huiping, DONG Qiang, PANG Nianchang, ZHANG Xiling* and SONG Meizhen*

\begin{abstract}
Background: Salt stress significantly inhibits the growth, development, and productivity of cotton because of osmotic, ionic, and oxidative stresses. Therefore, the screening and development of salt tolerant cotton cultivars is a key issue towards sustainable agriculture. This study subjected 11 upland cotton genotypes at the seedling growth stage to five different salt concentrations and evaluated their salt tolerance and reliable traits.

Results: Several morpho-physiological traits were measured after 10 days of salinity treatment and the salt tolerance performance varied significantly among the tested cotton genotypes. The optimal $\mathrm{NaCl}$ concentration for the evaluation of salt tolerance was $200 \mathrm{mmol} \cdot \mathrm{L}^{-1}$. Membership function value and salt tolerance index were used to identify the most consistent salt tolerance traits. Leaf relative water content and photosynthesis were identified as reliable indicators for salt tolerance at the seedling stage. All considered traits related to salt tolerance indices were significantly and positively correlated with each other except for malondialdehyde. Cluster heat map analysis based on the morpho-physiological salt tolerance-indices clearly discriminated the 11 cotton genotypes into three different salt tolerance clusters. Cluster I represented the salt-tolerant genotypes (Z9807, Z0228, and Z7526) whereas clusters II (Z0710, Z7514, Z1910, and Z7516) and III (Z0102, Z7780, Z9648, and Z9612) represented moderately salttolerant and salt-sensitive genotypes, respectively.

Conclusions: A hydroponic screening system was established. Leaf relative water content and photosynthesis were identified as two reliable traits that adequately represented the salt tolerance of cotton genotypes at the seedling growth stage. Furthermore, three salt-tolerant genotypes were identified, which might be used as genetic resources for the salt-tolerance breeding of cotton.
\end{abstract}

Keywords: Cotton genotypes, Salt stress, Screening, Membership function value, Cluster analysis

\section{Background}

Salinity is the second-most prevalent abiotic stress after drought, which not only limits plant growth but also progressively decreases the optimal yield of crops worldwide (Gao et al. 2016). Globally, more than 800 million hectares

\footnotetext{
*Correspondence: hainan1571@163.com; songmeizhencaas@163.com State Key Laboratory of Cotton Biology, Institute of Cotton Research of Chinese Academy of Agricultural Sciences, Anyang 455000, Henan, China
}

are invariably affected by salinity (Munns and Tester 2008). The salinity-affected zone increases as a result of climate change, sea level rise, and disproportionate surface irrigation in combination with inappropriate drainage systems (Kumar et al. 2013). It has been projected that if the current increase of salinity continues, $50 \%$ of the existing cultivated land will be affected by salinity stress by 2050 (Wang et al. 2003). In China, about 36 million hectares $(4.88 \%$ of the available land) are affected by salinity stress (Li et al. 2014).

(c) The Author(s). 2020 Open Access This article is licensed under a Creative Commons Attribution 4.0 International License, which permits use, sharing, adaptation, distribution and reproduction in any medium or format, as long as you give appropriate credit to the original author(s) and the source, provide a link to the Creative Commons licence, and indicate if changes were made. The images or other third party material in this article are included in the article's Creative Commons licence, unless indicated otherwise in a credit line to the material. If material is not included in the article's Creative Commons licence and your intended use is not permitted by statutory regulation or exceeds the permitted use, you will need to obtain permission directly from the copyright holder. To view a copy of this licence, visit http://creativecommons.org/licenses/by/4.0/. 
Currently, the global cultivable land is decreasing at an alarming rate and competition between cereal and fiber crops is progressively increasing. As a result, the cottongrowing area is increasingly relocated to saline and alkaline soils (Peng et al. 2018).

In general, salt-resistance is considered multifarious phenomena and plants have developed several mechanisms to counteract this form of stress at the cellular, subcellular and organ levels. The primary effect of salinity stress is osmotic stress, which starts by increasing $\mathrm{Na}^{+}$and $\mathrm{Cl}^{-}$concentrations in the root zone. Consequently, plants suffer ionic toxicity after the accumulation of salt in mature leaves as a result of transpiration (Munns and Tester 2008; Abdelraheem et al. 2019). Ion toxicity not only affects cellular metabolic processes but also impedes the photosynthetic unit of plants and induces oxidative damage. In case of prolonged stress, ion toxicity causes an initial biomass loss that may lead to programmed cell death (Sade et al. 2017). Moreover, the over-accumulation of toxic ions in a saline environment may enhance the disorder of $\mathrm{K}^{+} / \mathrm{Na}^{+}$ion homeostasis, accelerate the generation of reactive oxygen species (ROS), and thus, accelerate the proliferation of lipid peroxidation (Gill and Tuteja 2010; Sehar et al. 2019). Plants naturally cope with this condition by enhancing osmotic adjustment, regulating stomatal aperture, balancing ionic disequilibrium, increasing antioxidant activities, and maintaining the tissue water content (Peng et al. 2014; Farooq et al. 2015). However, salt tolerance is a relative measurement and the negative impacts of salt stress depend on various factors, such as the phase of plant growth, the duration of exposure to salinity, the salt concentration, the plant species, and/or the method of evaluation (Higbie et al. 2010).

Natural variation is the primary source for the development of a reliable index that applies for both wild-type and domestic germplasms. It is also helpful to provide an additional benefit towards understanding the underlying physiology and genetic mechanisms of tolerance at sensitive stages of plant growth (Ismail and Horie 2017). The correct phenotypic evaluation of genotypes is significant for salinity tolerance based on genetic approaches (Kakar et al. 2019). Different morpho-physiological indexes are responsible for the tolerance to salt stress. Kakar et al. (2019) used distinct morpho-physiological traits, such as plant height, tiller number, leaf area, root length, root surface area, chlorophyll contents, flavonoids, and nitrogen balance index, to evaluate the salt tolerance of rice at the seedling stage. They concluded that root parameters might be more reliable than other parameters. Al Kharusi et al. (2017) considered different physiological traits, including gas exchange parameters, chlorophyll fluorescence, sodium-potassium ion concentrations, relative water content, and electrolyte leakage ratio, to evaluate the salt tolerance of date palm cultivars. They summarized that $\mathrm{Na}^{+}$exclusion and photosynthesis represent the best-fitting traits for the evaluation of salt tolerance
Al Kharusi et al. 2017). According to Suriya-Arunroj et al. (2004), the relative water content of fully expanded youngest leaves could be used as a key indicator during the early growth stage of rice cultivars. Therefore, the morphophysiological indexes may collectively offer the most efficient approach for the evaluation of the salt tolerance of cotton genotypes.

For efficient salt-tolerance breeding, it is crucial to develop an efficient and functional evaluation method of salt tolerance (Ding et al. 2018). In general, cotton plants are more sensitive to salinity during the early seedling growth stage after the germination stage (Leidi and Saiz 1997; Ashraf and Ahmad 2000; Peng et al. 2018). The identification systems of salt tolerance at the seedling stage in cotton under salinity-stress conditions have already been established (Ye and Liu 1998; Liu et al. 2011; Ding et al. 2018). However, such screening methods are time- and laborconsuming. Moreover, the salt tolerance of cotton represents a multifaceted quantitative trait, and thus, any single index may not be sufficient to reflect the tolerance level. Membership function value (MFV) analysis was applied to evaluate the salt tolerance of Brassica napus (Wu et al. 2019) and a number of scholars have also suggested the regression-based analysis for salt-tolerance evaluation of different crop species, e.g., wheat (Chen et al. 2012) and sorghum (Ding et al. 2018). Therefore, to shorten the selection period, identify the procedure, and improve the reliability of evaluation, 11 cotton materials with differing biological characteristics (selected from preliminary work) were selected and studied to establish a salt-tolerance evaluation system under the condition of hydroponics. This study is (1) to determine the optimum salt concentration of selected cotton genotypes; (2) to identify reliable morpho-physiological traits for salt tolerance at the early seedling growth stage; and (3) to explore the genetic potentiality of cotton genotypes and to cluster these into different salt-tolerance groups.

\section{Methods \\ Plant materials, growth environments, and treatments}

The seeds of Gossypium hirsutum were collected by Professor Wuwei Ye's team of Institute of Cotton Research, Chinese Academy of Agricultural Sciences, Anyang, Henan, China. Genotypes were selected based on a previous selection experiment under salt pond conditions (Table 1). It is generally assumed that emergence and young seedling stages are very salt-sensitive stages in cotton (Peng et al. 2014), so this study investigated the traits at the seedling stage. Healthy and uniform seeds were selected and disinfected by $10 \%$ sodium hypochlorite solution for $5 \mathrm{~min}$ and carefully washed three times with deionized water. The seeds were sown at about $3 \mathrm{~cm}$ depth in sterilized wet sand 7 in plastic pots $(10 \mathrm{~cm} \times 10 \mathrm{~cm} \times 10 \mathrm{~cm})$. After 7 days of germination, vigorous and identical seedlings were enclosed in foam bands at the root-shoot junction and were transplanted 
Table 1 Plant materials information

\begin{tabular}{|c|c|c|}
\hline Names & Background & $\begin{array}{l}\text { Salt response in the } \\
\text { sand pond }\end{array}$ \\
\hline$Z 9807$ & This line derived from CCRI 7 & Tolerant \\
\hline Z0710 & This line derived from YU 2067 & Tolerant \\
\hline Z1910 & A hybrid progeny crossing between Ji851 and GKZ19 & Tolerant \\
\hline Z0228 & A hybrid offspring breeding between Ji Mian228 and 9807 & Tolerant \\
\hline Z7514 & A hybrid offspring crossing between Ji Mian616 and Ji Mian228 & Tolerant \\
\hline Z7516 & The line obtained from crossing between Yu Zao 97-1335 and Yu 2067 & Tolerant \\
\hline Z7526 & Derived from Zhong 75-y-17 & Tolerant \\
\hline Z0102 & $\begin{array}{l}\text { Crossing between Zhong } 9807 \text { and Zhong } 9612 \text { (F2 generation breeding). } \\
\text { Recombinant Inbred Lines formed by multi-generation selfing }\end{array}$ & Sensitive \\
\hline Z9612 & Selected from CCRI 12 & Sensitive \\
\hline $\mathrm{Z7780}$ & The progeny of GK50 & Sensitive \\
\hline Z9648 & Breeding between GK50 and SGK36 & Sensitive \\
\hline
\end{tabular}

to $7 \mathrm{~L}$ plastic boxes (12 plants per pot) filled with an aerated, modified half-strength Hoagland nutrient solution (2.0 $\mathrm{mmol} \cdot \mathrm{L}^{-1} \mathrm{Ca}\left(\mathrm{NO}_{3}\right)_{2}, 1.0 \mathrm{mmol} \cdot \mathrm{L}^{-1} \mathrm{KCl}, 0.25 \mathrm{mmol} \cdot \mathrm{L}^{-1}$ $\mathrm{KH}_{2} \mathrm{PO}_{4}, 1.0 \mathrm{mmol} \cdot \mathrm{L}^{-1} \mathrm{MgSO}_{4}, 0.05 \mathrm{mmol} \cdot \mathrm{L}^{-1}$ EDTA.Fe.Na, $23.1 \mu \mathrm{mol} \cdot \mathrm{L}^{-1} \quad \mathrm{H}_{3} \mathrm{BO}_{3}, \quad 4.55 \mu \mathrm{mol} \cdot \mathrm{L}^{-1} \quad \mathrm{MnCl}_{2} \cdot 4 \mathrm{H}_{2} \mathrm{O}$, $0.4 \mu \mathrm{mol} \cdot \mathrm{L}^{-1} \quad \mathrm{ZnSO}_{4} \cdot 7 \mathrm{H}_{2} \mathrm{O}, \quad 0.15 \mu \mathrm{mol} \cdot \mathrm{L}^{-1} \quad \mathrm{CuSO}_{4} \cdot 5 \mathrm{H}_{2} \mathrm{O}$, $\left.0.5 \mu \mathrm{mol} \cdot \mathrm{L}^{-1}\left(\mathrm{NH}_{4}\right)_{6} \mathrm{Mo}_{7} \mathrm{O}_{24} \cdot 4 \mathrm{H}_{2} \mathrm{O}\right)$ in triplicate for each treatment. Seedlings were grown in a growth chamber under $16 \mathrm{~h}$ light and $8 \mathrm{~h}$ dark cycle, at a temperature of $28-30{ }^{\circ} \mathrm{C}$, and $(60 \pm 5) \%$ relative humidity. The nutrient solution was replaced once per week throughout the experimental period to maintain the appropriate composition. The $\mathrm{pH}$ of the growth medium was maintained between 5.8 and 6.2. Evaporated water was refilled with de-ionized $\left(\mathrm{dH}_{2} \mathrm{O}\right)$ water every day to retain the target volume.

Seedlings were grown under non-saline conditions until they had three true leaves. Salinity treatment was initiated by providing various levels of $\mathrm{NaCl}(100,150,200$, and 250 $\mathrm{mmol} \cdot \mathrm{L}^{-1}$ ) along with controls (only nutrient solution). To avoid early lethal damage, $\mathrm{NaCl}$ was dissolved in the nutrient solution and the salt concentration was increased stepwise ( $25 \%$ of the maximum concentration on every alternative day) over a 7-day period. The salt stress treatment under hydroponic cultivation continued for 10 days, and then, plants were harvested and sampled (Fig. 1). The leaf samples were instantly frozen in liquid nitrogen at $-80^{\circ} \mathrm{C}$ for biochemical analysis. Different growth parameters, as well as ionic and physiological indices were recorded accordingly.

\section{Measurement of morpho-physiological parameters Growth traits}

Growth was evaluated in terms of shoot length (SL), leaf numbers (LN), leaf area (LA), and total biomass (TB) of cotton seedlings. Ten days after salt treatment, seedlings from

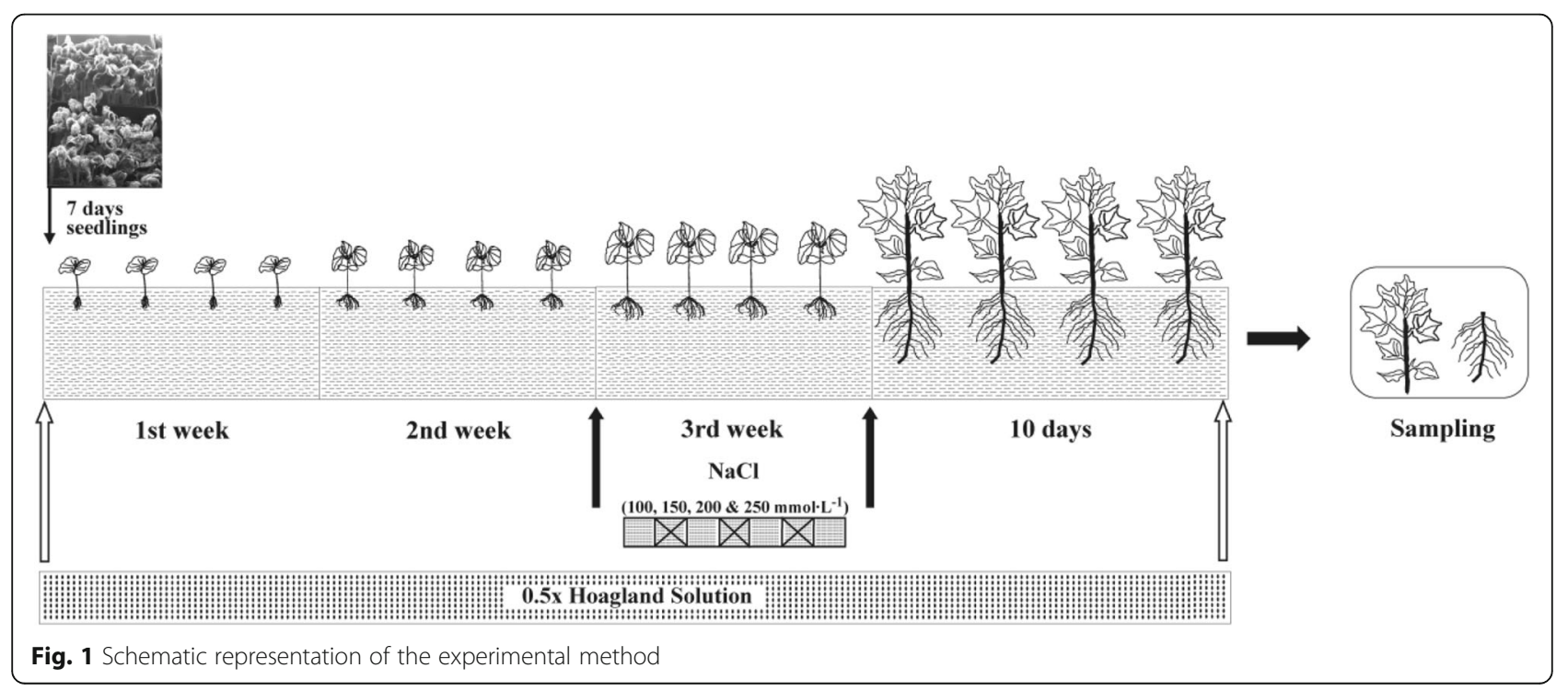


control and salt-treated genotypes were harvested. The morphological traits of five seedlings per replicate were measured. Shoot length was determined by computing the length from the cotyledon to the apex of the emerging leaf. The number of leaves was counted manually. For dry mass estimation, the fresh plant materials were cleaned with deionized water and divided into two parts (shoots and roots). Shoot and root parts were oven-dried at $105^{\circ} \mathrm{C}$ for $30 \mathrm{~min}$ followed by $80^{\circ} \mathrm{C}$ for $24 \mathrm{~h}$ until they maintained a constant weight. Shoot length was expressed in $\mathrm{cm}$ whereas $\mathrm{g}$ shoot $^{-1}$ was used to measure the biomass. A handheld leaf-area meter was used to calculate the leaf area (LI-3100, LI-COR, Inc., Lincoln, NE, USA).

\section{Determination of leaf relative water content}

The leaf relative water content (LRWC) was determined according to Barrs and Weatherley (1962). After collection, fresh leaves were immediately weighted as fresh weight (FW), then placed in a paper bag, and immersed in distilled water for $24 \mathrm{~h}$ under ambient light condition. The turgid weight (TW) was measured by removing all excess water from the leaves with the help of blotting paper. The dry weight (DW) was recorded after $48 \mathrm{~h}$ of oven drying at $80^{\circ} \mathrm{C}$. Finally, the LRWC was calculated based on the following equation:

$$
\text { LRWC }(\%)=[(\text { FW-DW }) /(\text { TW }-D W)] \times 100
$$

\section{Gas exchange parameters}

After 10 days of salt stress, gas exchanges parameters, such as photosynthetic rate (A) and stomatal conductance (gsw), were recorded in each plant by using a handheld photosynthesis system (LI-6800, LI-COR, Inc., Lincoln, NE, USA). All gas exchange parameters were measured with $6 \mathrm{~cm}^{2}$ of total leaf area from the top third fully spread leaf. The data were automatically collected after 4-5 min with at least four replicates.

\section{Assay of lipid peroxidation}

Lipid peroxidation as malondialdehyde (MDA) was measured from the third fully expanded frozen leaf (Shi et al. 2010). Approximately $0.3 \mathrm{~g}$ of fresh leaf samples were homogenized in $8 \mathrm{~mL}$ of $10 \%$ trichloroacetic acid (TCA) followed by centrifugation at $4000 \times g$ for $10 \mathrm{~min}$ at $4{ }^{\circ} \mathrm{C}$. To $2 \mathrm{~mL}$ aliquot of the supernatants, $2 \mathrm{~mL} 0.67 \%$ 2-thiobarbituric acid (TBA) were added and the mixture was placed in boiling water $\left(100^{\circ} \mathrm{C}\right)$ for $15 \mathrm{~min}$ and then immediately cooled in an ice bath. Finally, the absorption of the supernatant was measured by a spectrophotometer (UV-1280, Shimadzu, Japan) at 600, 532, and $450 \mathrm{~nm}$, respectively. The MDA content was calculated based on the following equation:

$$
\begin{aligned}
\mathrm{C}_{\mathrm{MDA}} & =6.45 \cdot\left(\mathrm{A}_{532}-\mathrm{A}_{600}\right)-0.56 \cdot \mathrm{A}_{450} \mathrm{MDA} \\
& =\mathrm{C}_{\mathrm{MDA}} \cdot \mathrm{N} /(\mathrm{W})
\end{aligned}
$$

where $\mathrm{C}_{\mathrm{MDA}}$ represents the colorimetric $\mathrm{MDA}\left(\mu \mathrm{mol} \cdot \mathrm{L}^{-1}\right)$, $\mathrm{N}$ represents the total volume of the supernatant $(\mathrm{mL})$, and
W represents the fresh sample mass (g). Finally, the MDA concentration was expressed as $\mu \mathrm{mol} \cdot \mathrm{g}^{-1} \mathrm{FW}$.

\section{Tissue elemental ion analysis}

Sodium and potassium ion contents were analyzed using the acid digestion method. Dried shoot (leaf and stem) and root samples were ground and passed through a 2-mm mesh sieve. Approximately $0.12 \mathrm{~g}$ of the ground powders were completely digested with $3 \mathrm{~mL}$ concentrated $\mathrm{H}_{2} \mathrm{SO}_{4}$ at $200^{\circ} \mathrm{C}$, supplemented with $1.0-1.5 \mathrm{~mL} \mathrm{H}_{2} \mathrm{O}_{2}$ (30\% v/v). After digestion, every sample was filled to $50 \mathrm{~mL}$ by adding distilled-deionized water to the final volume. Finally, the $\mathrm{Na}^{+}$ and $\mathrm{K}^{+}$contents were analyzed by flame spectrophotometer (FP 6410, Shanghai Precision Instruments Co., Ltd., China).

\section{Salt tolerance evaluation}

The salt tolerance level of the investigated cotton genotypes was assessed by MFV. The MFV of a fuzzy set is a simplification of the indicator function of ordinary sets and exemplifies the extent of reality as an extension of the evaluation (Chen et al. 2012).

The MFV value was calculated via the salt tolerance index (STI), using the following formula:

$$
\mathrm{STI}=\mathrm{STP} / \mathrm{CP}
$$

where stressed plants (STP) represents the mean value of a single trait under salt stress and control plants $(\mathrm{CP})$ represents the mean value of a single trait under nonsaline treatment.

MFV was computed using the following equation:

$$
\mathrm{X}_{\mathrm{i}}=\left(\mathrm{X}-\mathrm{X}_{\min }\right) /\left(\mathrm{X}_{\max }-\mathrm{X}_{\min }\right) \cdot 100 \%
$$

where $X_{i}$ represents the membership function value of the specific cotton genotype; $\mathrm{X}$ represents the definite measured value of the salt tolerance index in a specific genotype, and $\mathrm{X}_{\max }$ and $\mathrm{X}_{\min }$ represent the maximum and minimum values observed in all-cotton genotypes, respectively (Wu et al. 2019).

The salt tolerance of genotypes was evaluated according to the mean MFVs of each trait and the MFVs of all studied cotton genotypes, ranging from 0 to 1 . For each cotton genotype, the mean of MFV was computed as the average of the MFVs of all morpho-physiological traits. A higher mean value of MFV indicated a higher salt tolerance level.

According to Wu et al. (2019), the salt damage index (SDI) was calculated according to the following equation: $\mathrm{SDI}=1$ - STI.

\section{Statistical analysis}

Data analysis was performed using SPSS 25.0 (SPSS Inc., USA) and differences between treatments were assessed by ANOVA (Analysis of variance), followed by 
DMRT (Duncan's multiple range test). Data were considered significantly different at $P<0.05$.

\section{Results}

\section{Determination of optimum salt concentration}

In this study, 11 cotton genotypes were subjected to four different salt concentrations and one control treatment to identify the target salt concentration. The SDI of different morpho-physiological traits, such as SL, LN, LA, TB, LRWC, A, gsw, MDA, $\mathrm{SK}^{+} / \mathrm{Na}^{+}$, and $\mathrm{RK}^{+} / \mathrm{Na}^{+}$, were calculated accordingly. The results were interpreted by linear regression analysis (Fig. 2). When cotton seedlings were treated with $181.5 \mathrm{mmol} \cdot \mathrm{L}^{-1} \mathrm{NaCl}$, the SDI of SL decreased to $50 \%$ of the total SDI value. Similarly, other traits (e.g., LN, LA, TB, LRWC, A, gsw, MDA, $\mathrm{SK}^{+} / \mathrm{Na}^{+}$, and $\mathrm{RK}^{+} / \mathrm{Na}^{+}$) decreased to $50 \%$ of the total SDI in response to treatments with 186.0,

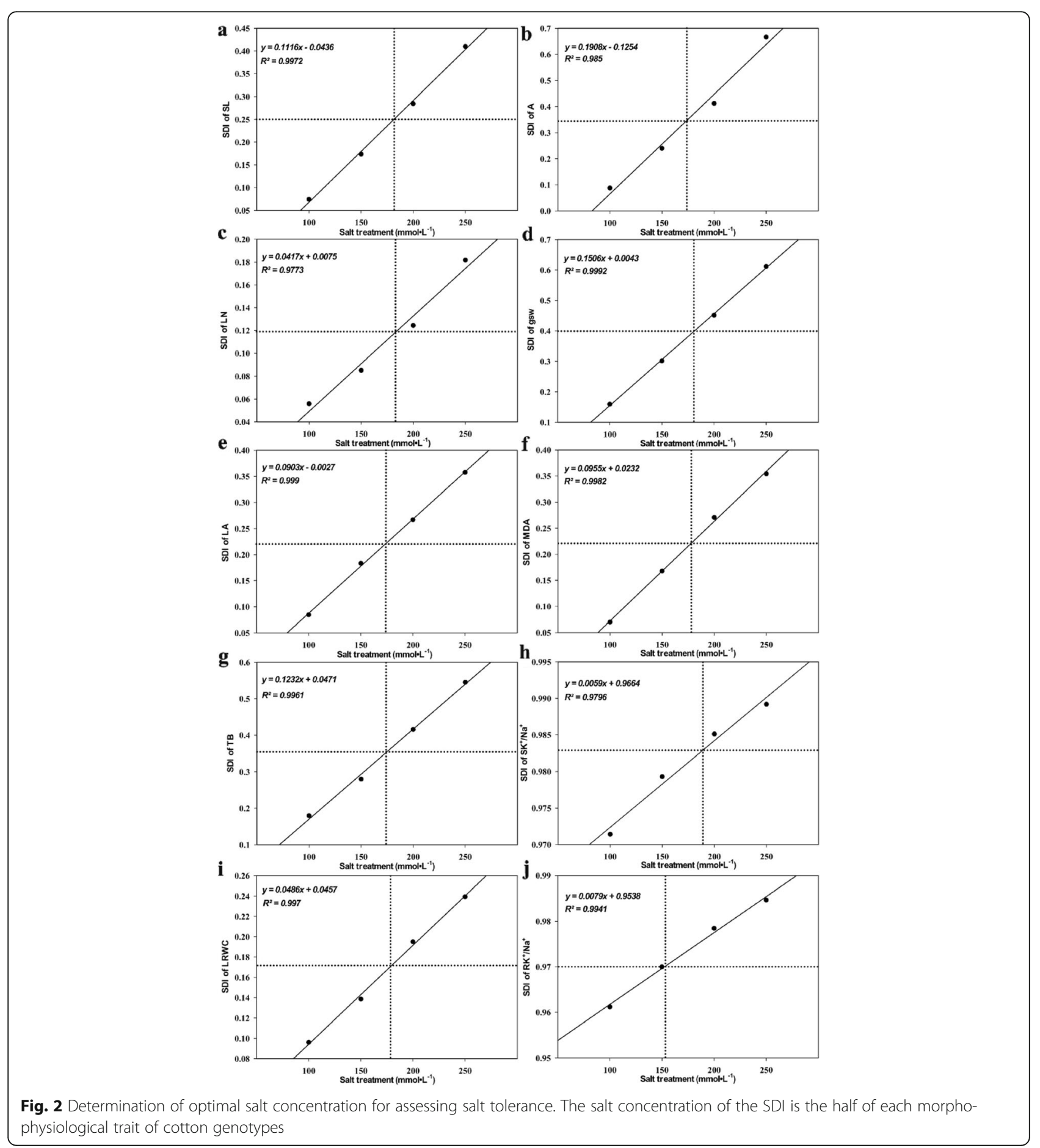



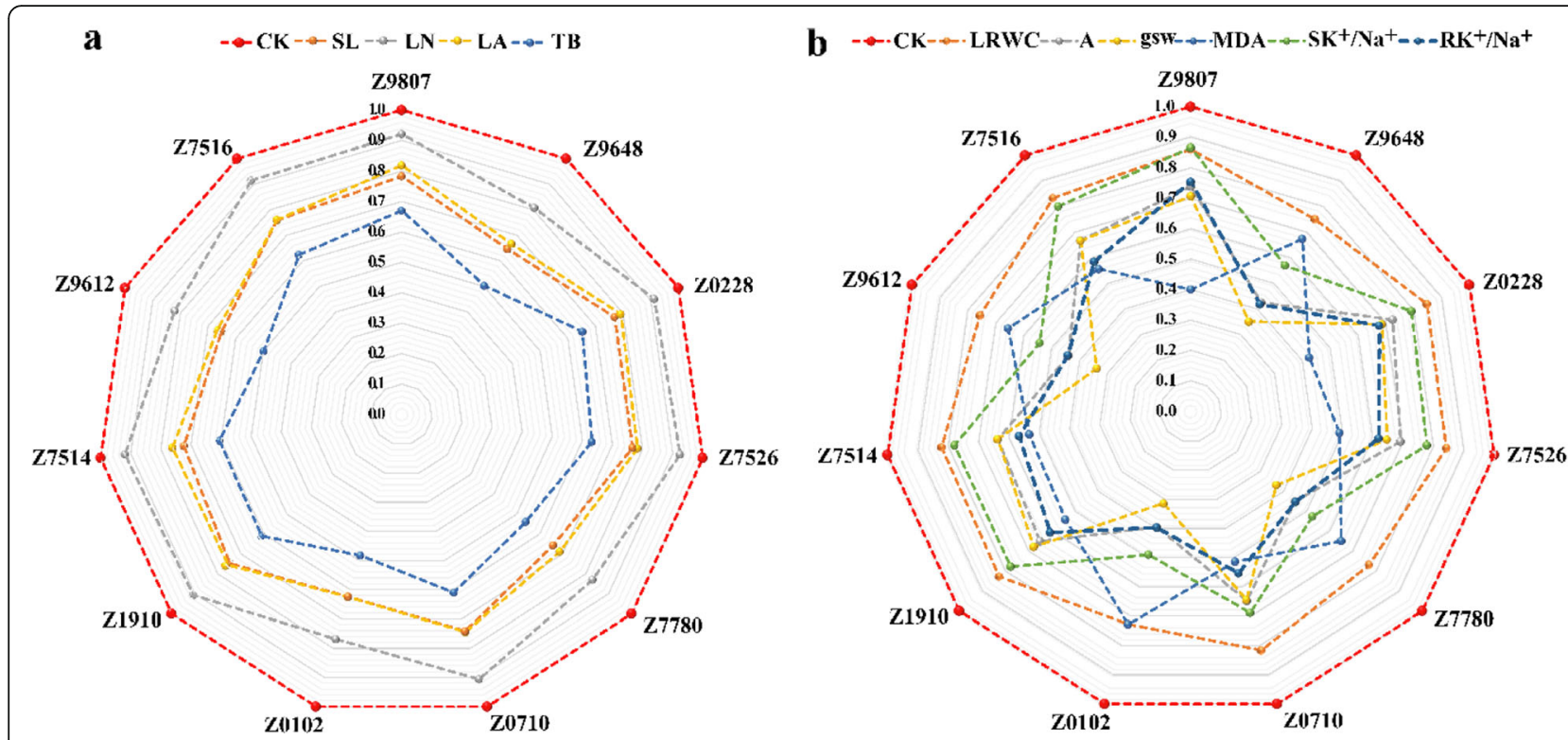

Fig. 3 Radar plot represents the genotypic variations in different morphological (a) and physiological (b) traits in the presence of $200 \mathrm{mmol} \cdot \mathrm{L}^{-1}$ $\mathrm{NaCl}$ treatment

172.0, 173.5, 180.0, 175.2, 170.0, 155.0, 188.1, and 177.1 $\mathrm{mmol} \cdot \mathrm{L}^{-1} \mathrm{NaCl}$, respectively. The average salt concentration of all investigated parameters against SDI was 175.81 $\mathrm{mmol} \cdot \mathrm{L}^{-1}$. Therefore, a salt concentration of $200 \mathrm{mmol} \cdot \mathrm{L}^{-1}$ was selected for the current study to compare the salt tolerance among the 11 tested cotton genotypes.

\section{Genotypic variation under salt stress}

Radar plot analysis based on STI values showed that the cotton genotype exhibited varying responses under salt treatment (Fig. 3a and b). The genotypes Z9807, Z0228, and Z7526 achieved the highest average STI values, while the genotype Z0102 exhibited the lowest STI compared with other cotton genotypes for all considered traits except for the MDA content (Table 2). The STI of the MDA content was high in Z0102, Z9648, Z9612, and Z7780 genotypes, while Z9807 accumulated the lowest MDA under salt stress (Fig. 3b). Additionally, the $\mathrm{K}^{+} / \mathrm{Na}^{+}$ratio assumed a pivotal role in ion homeostasis under salt stress conditions. Genotype $\mathrm{Z} 9807$ retained a higher $\mathrm{K}^{+} / \mathrm{Na}^{+}$ratio than all other investigated cotton genotypes by maintaining a higher STI value in both shoot and root tissues.

\section{Correlation analysis under salt stress}

The correlation coefficient of all studied morphophysiological traits under salt treatment was analyzed by Pearson's correlation (Table 3). All examined parameters related to salt tolerance indices exhibited significant and

Table 2 Salt tolerance verification with their mean MFVs

\begin{tabular}{|c|c|c|c|c|c|c|c|c|c|c|c|}
\hline \multirow[t]{2}{*}{ Genotypes } & \multicolumn{10}{|c|}{ STI value } & \multirow{2}{*}{$\begin{array}{l}\text { Mean } \\
\text { of } \\
\text { MFV }\end{array}$} \\
\hline & $\overline{\mathrm{SL}}$ & $\mathrm{LN}$ & LA & $\mathrm{TB}$ & LRWC & A & gsw & $\mathrm{MDA}$ & $\mathrm{SK}^{+} / \mathrm{Na}^{+}$ & $\mathrm{RK}^{+} / \mathrm{Na}^{+}$ & \\
\hline Z9807 & 0.783 & 0.921 & 0.819 & 0.671 & 0.861 & 0.739 & 0.707 & 0.400 & 0.866 & 0.754 & 0.897 \\
\hline Z9648 & 0.645 & 0.807 & 0.667 & 0.503 & 0.750 & 0.425 & 0.351 & 0.673 & 0.570 & 0.418 & 0.239 \\
\hline Z0228 & 0.770 & 0.913 & 0.792 & 0.653 & 0.847 & 0.724 & 0.686 & 0.425 & 0.792 & 0.677 & 0.803 \\
\hline Z7526 & 0.767 & 0.925 & 0.783 & 0.632 & 0.843 & 0.692 & 0.647 & 0.490 & 0.779 & 0.620 & 0.756 \\
\hline Z7780 & 0.658 & 0.830 & 0.688 & 0.539 & 0.770 & 0.449 & 0.369 & 0.650 & 0.526 & 0.453 & 0.307 \\
\hline Z0710 & 0.741 & 0.906 & 0.745 & 0.610 & 0.817 & 0.649 & 0.645 & 0.514 & 0.689 & 0.553 & 0.653 \\
\hline Z0102 & 0.625 & 0.769 & 0.625 & 0.483 & 0.728 & 0.395 & 0.314 & 0.729 & 0.490 & 0.397 & 0.100 \\
\hline Z1910 & 0.748 & 0.907 & 0.756 & 0.610 & 0.828 & 0.651 & 0.679 & 0.542 & 0.778 & 0.607 & 0.690 \\
\hline Z7514 & 0.723 & 0.919 & 0.761 & 0.605 & 0.822 & 0.637 & 0.637 & 0.533 & 0.779 & 0.566 & 0.688 \\
\hline Z9612 & 0.652 & 0.820 & 0.667 & 0.499 & 0.757 & 0.439 & 0.338 & 0.656 & 0.542 & 0.441 & 0.220 \\
\hline Z7516 & 0.759 & 0.915 & 0.760 & 0.624 & 0.833 & 0.667 & 0.666 & 0.556 & 0.801 & 0.584 & 0.718 \\
\hline
\end{tabular}


positive correlations with each other, except for the MDA content of leaves. Among all traits, LRWC showed the highest positive and negative correlation with most of the traits; e.g., between LRWC and MDA, the strongest $(-0.803)$ negative correlation was observed. In contrast, the most significant positive correlations were observed among LRWC and $\mathrm{SK}^{+} / \mathrm{Na}^{+}$(0.918), $\mathrm{RK}^{+} / \mathrm{Na}^{+}$(0.917), A (0.900), and $\mathrm{LN}$ (0.819). Moreover, A and gsw showed a strong positive correlation (0.939) with each other along with total biomass production $(0.830$ and 0.865$)$ and LRWC (0.876) of saltstressed cotton seedlings. The results of the Pearson's correlation coefficient also supported the result of cluster analysis.

\section{Determining reliable salt tolerance traits}

To identify the most suitable salt tolerance traits, a linear regression fit was performed using the STI of distinct traits and the average membership function value (Fig. 4). The results of this analysis indicated that the mean MFV value was affected by the STI value, and the higher the STI value of each trait, the higher the MFV value (except for MDA). The highest regression value was observed in the LRWC $\left(R^{2}=\right.$ $0.9921)$ followed by A $\left(R^{2}=0.9873\right)$ between the average of MFV and STI value, while $\mathrm{RK}^{+} / \mathrm{Na}^{+}$had the lowest regression value $\left(R^{2}=0.9196\right)$. The regression values of TB, LA, $\mathrm{SL}$, gsw, $\mathrm{SK}^{+} / \mathrm{Na}^{+}, \mathrm{LN}$, and MDA were $0.9867,0.9839$, 0.978 5, 0.965 4, $0.9535,0.949$ 3, and 0.922 3, respectively. Overall, these results indicated that both LRWC and photosynthesis can be considered as two potential traits for the salt tolerance evaluation of cotton genotypes at the seedling growth stage.

\section{Cluster heat map analysis}

To categorize the genotypes into a homogenous group based on their morpho-physiological traits, cluster heat map analysis was performed, using the Euclidean squared distance metric (Fig. 5). According to the potential characteristics of the genotypes, the studied 11 cotton genotypes were clustered into three statistically significant clusters.
Cluster I represented the salt-tolerant group, which was composed of the genotypes Z9807, Z0228, and Z7526. Genotypes Z7516, Z1910, Z7514, and Z0710 were clustered into cluster II, which represented a moderately salttolerant group. Cluster III included the genotypes Z0102, Z7780, Z9612, and Z9648, and represented the saltsensitive group. However, genotype Z9807 showed the highest STI, while genotype Z0102 showed the lowest STI within cluster I and cluster III, respectively.

\section{Discussion}

Salinity significantly affects growth-related traits by decreasing shoot length, leaf numbers, and leaf area, which collectively decreased the photosynthetic rate and subsequently the total biomass. Leaf area has been identified as an instantaneous response to stress condition (Zhang et al. 2014). The decreased leaf area under salt stress changes the leaf cellular structure, which results in a decrease of the net photosynthetic rate (Munns and Tester 2008). Moreover, biomass production under stress condition represents a prime attribute with which to assess the extent of the stress (Gong et al. 2013). In the current study, all cotton genotypes significantly decreased their total biomass production under salt stress, and significant decrease was found in genotypes Z0102, Z9648, Z9612, and Z7780. These genotypes were identified as saltsensitive ones (Fig. 3a). Several previous reports have suggested that salt tolerant plants showed less biomass reduction and better growth under salt stress compared with salt-sensitive plants (Ahmed et al. 2013; Singh and Sarkar 2014; Chiconato et al. 2019). The reason may be primarily attributed to the functional impairment of the osmotic potential, followed by ionic imbalance, predictably leading to a nutritional disproportion in plants (Meloni et al. 2001; Alharby et al. 2019). Another possible mechanism for the lower biomass accumulation may be the diversion and/or exchange of potential energy from plant growth to sodium ion exclusion. Alternative mechanisms are the synthesis of

Table 3 Pearson's correlation among different traits of cotton genotypes in the presence of $200 \mathrm{mmol} \cdot \mathrm{L}^{-1} \mathrm{NaCl}$ treatment

\begin{tabular}{|c|c|c|c|c|c|c|c|c|c|c|}
\hline Traits & $\mathrm{SL}$ & LN & LA & TB & LRWC & A & gsw & $\mathrm{MDA}$ & $\mathrm{SK}^{+} / \mathrm{Na}^{+}$ & $\mathrm{RK}^{+} / \mathrm{Na}^{+}$ \\
\hline SL & 1 & & & & & & & & & \\
\hline LN & $0.868^{\mathrm{a}}$ & 1 & & & & & & & & \\
\hline LA & $0.675^{a}$ & $0.705^{a}$ & 1 & & & & & & & \\
\hline TB & $0.767^{a}$ & $0.778^{a}$ & $0.869^{a}$ & 1 & & & & & & \\
\hline LRWC & $0.721^{a}$ & $0.819^{a}$ & $0.728^{a}$ & $0.713^{\mathrm{a}}$ & 1 & & & & & \\
\hline A & $0.775^{\mathrm{a}}$ & $0.834^{\mathrm{a}}$ & $0.770^{\mathrm{a}}$ & $0.830^{\mathrm{a}}$ & $0.900^{\mathrm{a}}$ & 1 & & & & \\
\hline gsw & $0.783^{a}$ & $0.844^{\mathrm{a}}$ & $0.798^{\mathrm{a}}$ & $0.865^{\mathrm{a}}$ & $0.876^{a}$ & $0.939^{a}$ & 1 & & & \\
\hline MDA & $-0.676^{a}$ & $-0.781^{a}$ & $-0.571^{a}$ & $-0.492^{a}$ & $-0.803^{a}$ & $-0.762^{\mathrm{a}}$ & $-0.673^{a}$ & 1 & & \\
\hline $\mathrm{SK}^{+} / \mathrm{Na}^{+}$ & $0.756^{\mathrm{a}}$ & $0.758^{\mathrm{a}}$ & $0.797^{\mathrm{a}}$ & $0.785^{\mathrm{a}}$ & $0.918^{\mathrm{a}}$ & $0.856^{\mathrm{a}}$ & $0.833^{\mathrm{a}}$ & $-0.707^{\mathrm{a}}$ & 1 & \\
\hline $\mathrm{RK}^{+} / \mathrm{Na}^{+}$ & $0.757^{a}$ & $0.755^{\mathrm{a}}$ & $0.785^{a}$ & $0.788^{\mathrm{a}}$ & $0.917^{\mathrm{a}}$ & $0.869^{a}$ & $0.839^{a}$ & $-0.711^{a}$ & $0.995^{\mathrm{a}}$ & 1 \\
\hline
\end{tabular}

${ }^{\mathrm{a}}$ Correlation is significant at the 0.01 level 

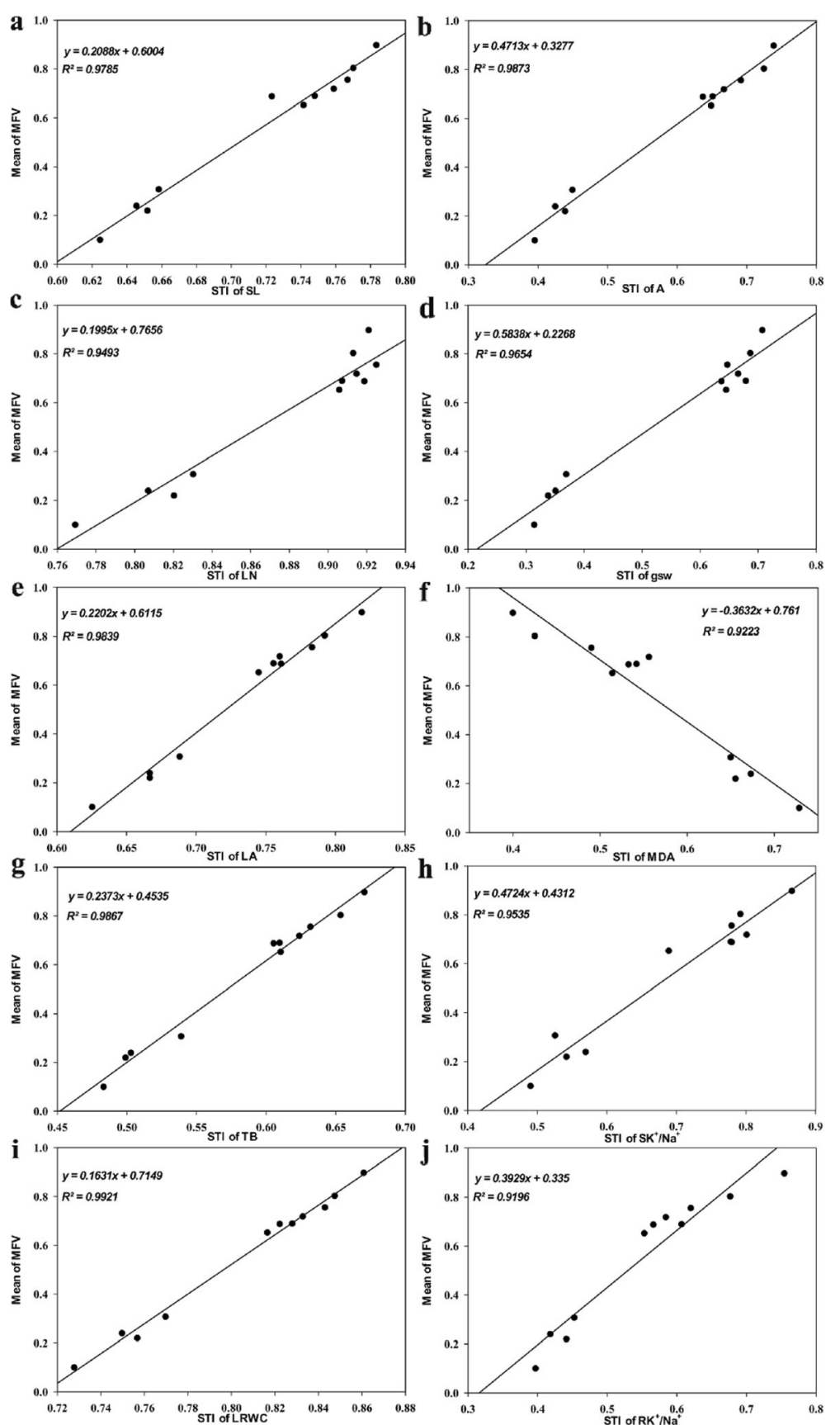

Fig. 4 The linear fit regression between STI of each morpho-physiological trait and mean MFV of cotton genotypes

compatible solutes (Munns and Tester 2008) or the direct effect of decreased photosynthesis (Haider et al. 2019). Similar inhibitions of growth and developmen induced by salt-stress have been reported for salt-stressed tomato (Gong et al. 2013), wheat (Elkelish et al. 2019), melon (Sarabi et al. 2017), and maize (Hessini et al. 2019).

The relationship between photosynthesis and salt stress is remarkably complex, and depends on the salt concentration, the duration of salt stress in the growth medium, and species (Chiconato et al. 2019). The potential reduction of stomatal conductance may also inhibit the photosynthetic capacity in most glycophytes, including cotton (Brugnoli and Lauteri 1991). In the present study, the photosynthetic rate decreased significantly with increasing salt concentration in the growth media. The genotypes Z9807, Z0228, and Z7526 showed the lowest photosynthesis reduction compared with control (Fig. 3b). 


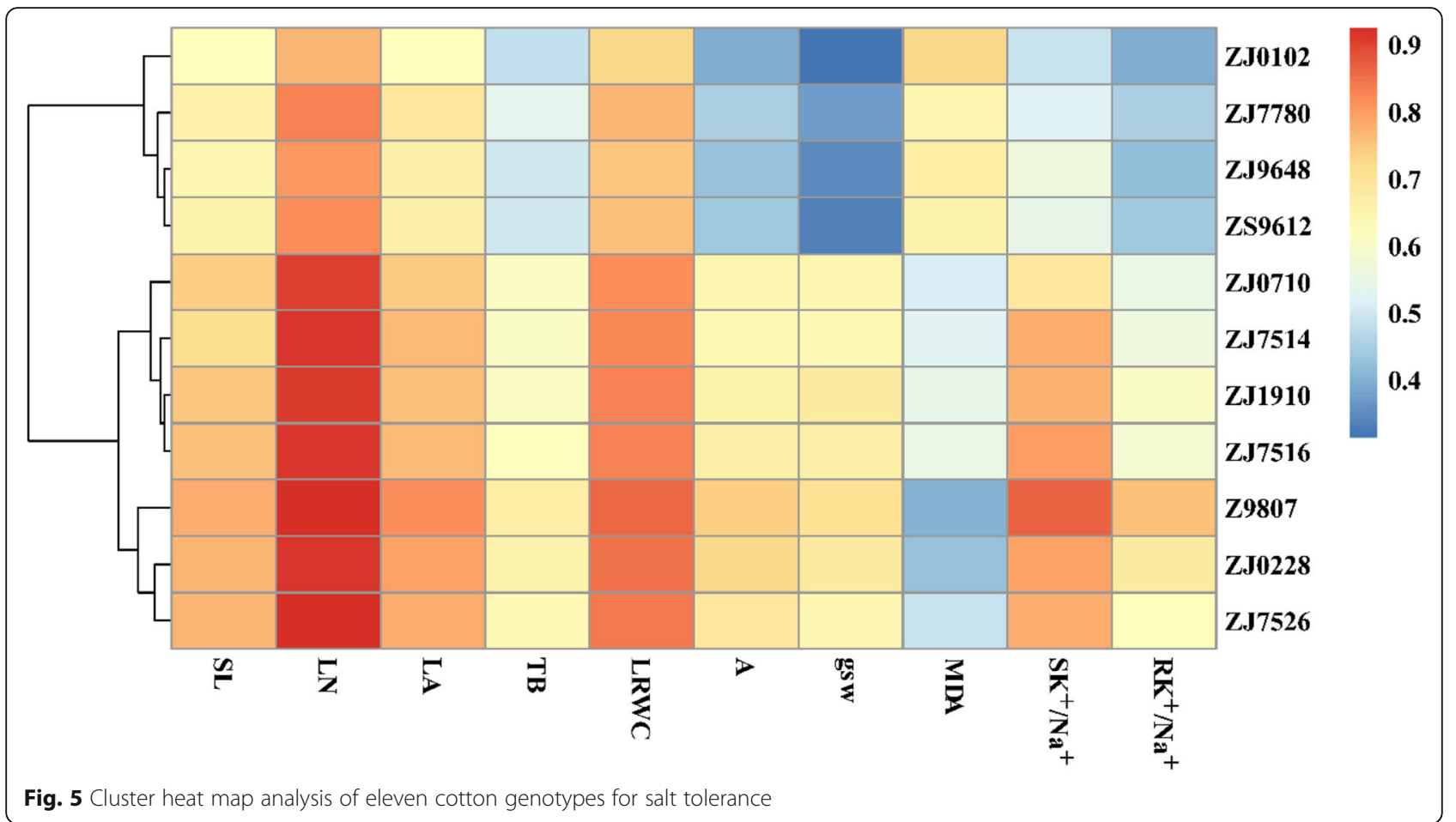

This result indicated that these three genotypes were able to maintain a higher photosynthetic rate by up-regulating their rubisco activity. Similar findings were reported in salt-stressed cotton genotypes, e.g., the salt-tolerant genotype CCRI-79 maintained the maximum photosynthetic rate compared with the salt-sensitive genotype Simian-3 (hang et al. 2014). The gsw also decreased under salt treatment (Kawakami et al. 2013) and a significant decrease was also observed in the present study. The possible mechanism of gsw reduction under salt stress may be the increase of abscisic acid levels (He and Cramer 1996) and/ or the decrease of stomatal aperture (Ahmed et al. 2013). This effect has also been reported for salt-stressed cotton (Kawakami et al. 2013; Zhang et al. 2014), pepper (Penella et al. 2015), date palm (Al Kharusi et al. 2017), melon (Sarabi et al. 2019), and sugarcane (Chiconato et al. 2019).

The LRWC is a key physiological trait that can also be used as an important indicator to discriminate the salt tolerance ability among genotypes (Sinclair and Ludlow 1986; Sánchez-Rodríguez et al. 2010). Under salt stress, the water potential decreases and inhibits the uptake of water by the roots, thus decreasing the LRWC (Munns and Tester 2008; Hassanvand et al. 2019). In the current study, the LRWC decreased prominently in the saltsensitive group (Z0102, Z9648, Z9612, and Z7780) compared with the salt-tolerant group. Previous studies corroborated this result, suggesting that salt-sensitive genotypes may not be able to uphold the water status as they accumulate more soluble salts compared with salt- tolerant genotypes (Al Kharusi et al. 2017; Sarabi et al. 2017; Aghaie et al. 2018). Furthermore, a highly significant positive correlation was found between the LRWC and the shoot-root $\mathrm{K}^{+} / \mathrm{Na}^{+}$ratio (Table 3). This indicated that plants with a higher $\mathrm{K}^{+} / \mathrm{Na}^{+}$ratio retained more water in their leaf tissues under salt stress.

Salt stress primarily affects plants by osmotic stress, which is followed by ionic stress and perturbed ion homeostasis, resulting in a change of metabolic and cellular acclimation in plant physiology (Fig. 6). $\mathrm{Na}^{+}$is often considered as the most toxic ion in a saline environment because of its excessive cytosolic concentration; moreover, frequent $\mathrm{Na}^{+}$accumulation is also deleterious for plants (Munns and Tester 2008; Munns et al. 2016). To avoid excessive $\mathrm{Na}^{+}$, salt exclusion and/or ion sequestration into vacuoles represent prominent mechanisms of salt-stress adaptation (Liu et al. 2018; Wang et al. 2019). In the present study, all cotton genotypes accumulated inorganic $\mathrm{Na}^{+}$at different extents. Salt tolerance genotypes maintained higher $\mathrm{K}^{+} / \mathrm{Na}^{+}$ratios compared with salt-sensitive genotypes such as Z0102. Specifically, salt-tolerant genotypes exhibited the highest $\mathrm{K}^{+} / \mathrm{Na}^{+}$ratios in the shoot and root tissues. This might be the result of the induction of salt-related genes, such as SOS1 and HKT1, which prevented excessive $\mathrm{Na}^{+}$loading in the xylem sap, thus reduced the accumulation of lethal $\mathrm{Na}^{+}$and maintaining the proper $\mathrm{K}^{+}$ratio in cells (Assaha et al. 2017). This result corroborates other research findings (Tester and Davenport 2003; Chen et al. 2005; Rahneshan et al. 2018). 


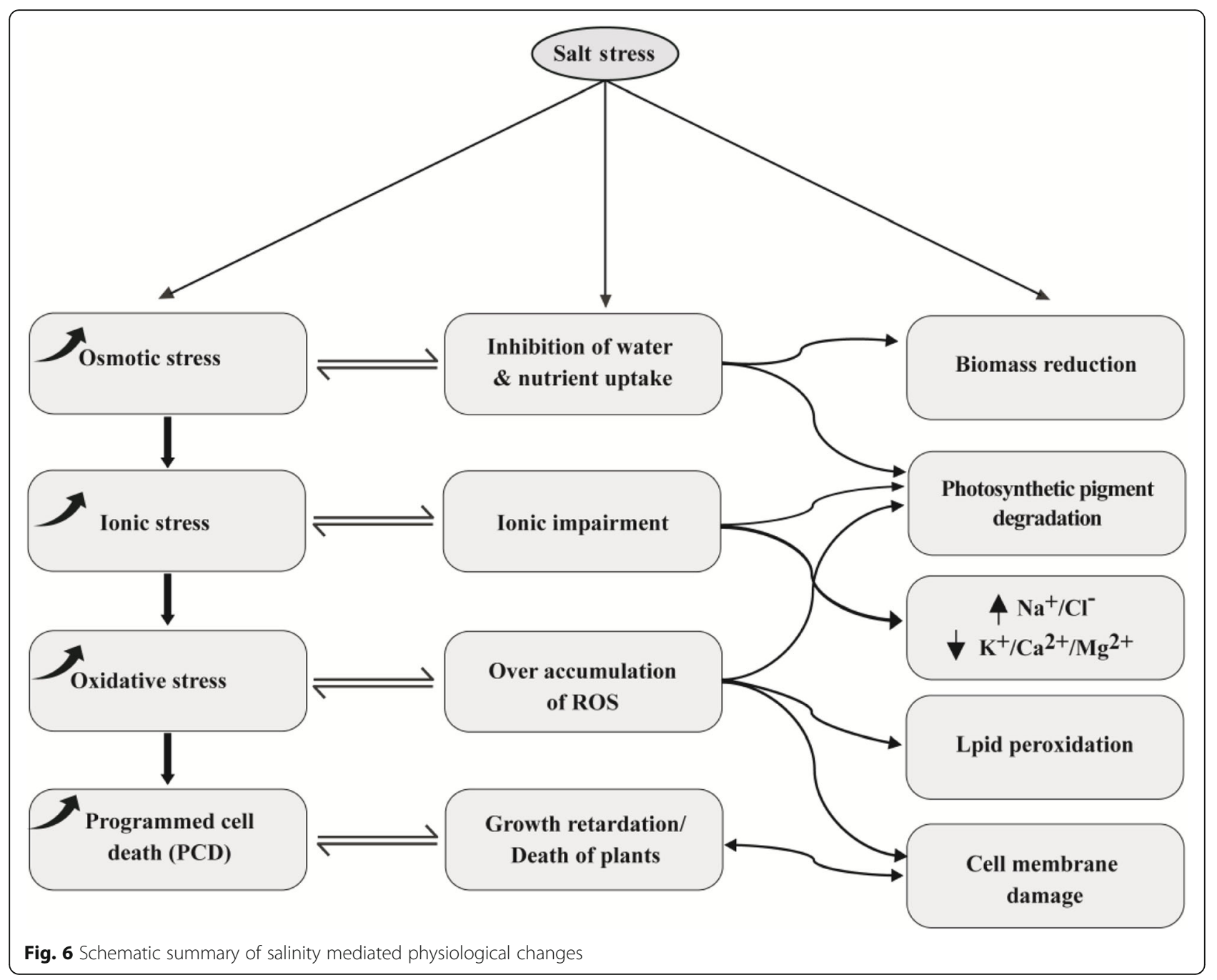

Apart from inorganic ion homeostasis, salt stress generates ROS, thus causing oxidative damage as secondary damage in plant cells. Excessive accumulation of ROS in salt-treated cotton seedlings might accelerate the HaberWeiss reaction and consequently amplify both lipid peroxidation and cell membrane damage (Gill and Tuteja 2010; Borzouei et al. 2012). As expected, the leaf MDA content was lowest in genotype Z9807, whereas the highest induction was observed in genotype Z0102 grown under salt stress for 10 days (Fig. 3b). The lowest MDA accumulation under salt stress was also observed in the salt-tolerant CSSL line of rice compared with the salt-sensitive CSSL line (Nounjan and Theerakulpisut 2012). This result agrees with the results reported for other plant species, such as strawberry (Garriga et al. 2015), melon (Sarabi et al. 2017), rice (Wang et al. 2018), and mungbean (Alharby et al. 2019). Moreover, a highly significant negative correlation was observed between MDA content and LRWC as well as photosynthesis (Table 3), suggesting lipid peroxidation, caused by salt stress, as one of the main reasons for the decrease of the tissue-water content and photosynthetic rate in cotton genotypes.

Salt stress perturbs the morphological, physiological, and biochemical changes of plants at the seedling growth stage. A number of parameters should be assessed for an appropriate evaluation of salt tolerance; however, not all traits may be effective or reliable for the screening of genotypes. It is also well known that the evaluation process for reliable salt-tolerance traits is the crux of a successful salt-tolerance breeding program (Zeng et al. 2002). Therefore, such evaluation process is needed to identify a reliable salt-tolerance screening method for the effective evaluation of the salt tolerance of cotton genotypes at the seedling growth stage. The current study performed a multiple regression analysis to identify reliable salt-tolerance traits between the mean MFV and the STI of each individual morphophysiological trait of the studied cotton genotypes. The mean MFV was calculated based on the average of 
MFVs of shoot length, leaf numbers, leaf area, total biomass, photosynthesis, stomatal conductance, malondialdehyde content, as well as shoot and root $\mathrm{K}^{+} / \mathrm{Na}^{+}$ratios of each genotype. The average MFV was considered as multiple indicators to assess the salt tolerance of plants, higher MFV value indicates a higher salt-tolerance level (Table 2). According to the data obtained by the present study, the STI of LRWC $\left(R^{2}=0.9921\right)$ and $\mathrm{A}\left(R^{2}=\right.$ 0.982 3) represent reliable traits compared with the other eight morpho-physiological traits, based on the regression value between the mean of MFV and multiple indexes (Fig. 4). Thus, both the LRWC and photosynthesis traits might be used as reliable indicators for the salt-tolerance assessment of cotton genotypes at the seedling stage. In a previous study, Suriya-Arunroj et al. (2004) suggested that LRWC could be used as an effective indicator for the salt-tolerance evaluation of rice at the seedling stage. Another study recommended the root and shoot lengths as primary indicators for the salt tolerance of Brassica napus (Long et al. 2013).

Cluster heat map analysis was performed to classify the genotypes into homogenous groups based on the STI value of all studied traits. According to the results of this cluster analysis, the 11 cotton genotypes were divided into three major clusters with respect to their salttolerance levels (Fig. 5). In earlier studies, cluster analysis distinguished 12 rice cultivars (Chunthaburee et al. 2015) and eight almond species (Sorkheh et al. 2012) into four and three major clusters, respectively, based on their physiological traits. The result of the present study showed that the genotypes of cluster I exhibited superior performance under salt stress and achieved higher LRWC, photosynthesis, total biomass production, and higher shoot-root $\mathrm{K}^{+} / \mathrm{Na}^{+}$ratios compared with other genotypes (grouped within the other two clusters). Moreover, lower MDA content caused less oxidative damage in these genotypes, which could also be used as an indicator for salt-tolerant genotypes. This result also suggests cluster analysis as an important data-mining tool for discriminating cotton genotypes according to their salt-tolerance levels based on their morphophysiological features. This should be further investigated at different growth stages of cotton plants to explore the genotypic discrimination in response to salt stress.

\section{Conclusions}

In conclusion, the results of this study identified substantial effects of salt stress on the studied traits, and a noteworthy genotypic difference was found. Screening clearly identified three distinct groups: salt tolerant (showing superior tolerance), moderately salt tolerant (showing intermediate tolerance), and salt sensitive (showing susceptibility to salinity). Within the salt- tolerant groups, Z9807 showed the best tolerance potential, followed by Z0228 and Z7526. This suggests that these genotypes are prominent resources because of their salt tolerance, and could thus be used as genetic materials for the further breeding framework. In addition, LRWC and A were identified as two reliable salt-tolerance traits with which the cotton genotypes at the seedling growth stage can be evaluated. Therefore, these findings contribute to the breeding program of salt-tolerant cotton genotypes.

\section{Abbreviations}

A: Photosynthetic rate; gsw: Stomatal conductance; LA: Leaf area; LN: Leaf number; LRWC: Leaf relative water content; MDA: Malondialdehyde; MFV: Membership function value; $\mathrm{RK}^{+} / \mathrm{Na}^{+}$: Root potassium sodium ratio; SDI: Salt damage index; $\mathrm{SK}^{+} / \mathrm{Na}^{+}$: Shoot potassium sodium ratio; SL: Shoot length; STI: Salt tolerance index; TB: Total biomass

\section{Authors' contributions}

Sikder RK conducted the experiment and drafted the manuscript. Wang XR performed part of the statistical analysis and revised the manuscript. Jin DS assisted in data collection and part of the biochemical analysis. Zhang $\mathrm{HH}$ helped to prepare the graphs. Gui HP, Dong Q, and Pang NC helped with data collection. Song MZ and Zhang XL conceived the study, participated in its design, and helped to revise the manuscript. All authors read and approved the final manuscript.

\section{Funding}

This research was supported by National Key R \& D Program (2017YFD0101600) and State Key Laboratory of Cotton Biology (CB2019C17).

Availability of data and materials

All data generated or analyzed during this study are included in this published article.

Ethics approval and consent to participate Not applicable.

Consent for publication

Not applicable.

\section{Competing interests}

The authors declare that they have no competing interests.

Received: 13 December 2019 Accepted: 4 March 2020

Published online: 19 April 2020

\section{References}

Abdelraheem A, Esmaeili N, O'Connell M, et al. Progress and perspective on drought and salt stress tolerance in cotton. Ind Crop Prod. 2019;130:118-29. https://doi.org/10.1016/j.indcrop.2018.12.070.

Aghaie P, Tafreshi SA, Ebrahimi MA, et al. Tolerance evaluation and clustering of fourteen tomato cultivars grown under mild and severe drought conditions. Sci Hortic. 2018;232:1-12. https://doi.org/10.1016/j.scienta.2017.12.041.

Ahmed IM, Dai H, Zheng W, et al. Genotypic differences in physiological characteristics in the tolerance to drought and salinity combined stress between Tibetan wild and cultivated barley. Plant Physiol Biochem. 2013;63: 49-60. https://doi.org/10.1016/j.plaphy.2012.11.004.

Al Kharusi L, Assaha D, Al-Yahyai R, et al. Screening of date palm (Phoenix dactylifera L.) cultivars for salinity tolerance. Forests. 2017;8(4):136. https://doi. org/10.3390/f8040136.

Alharby HF, Al-Zahrani HS, Hakeem KR, et al. Identification of physiological and biochemical markers for salt $(\mathrm{NaCl})$ stress in the seedlings of mungbean [Vigna radiata (L.) Wilczek] genotypes. Saudi J Biol Sci. 2019;26(5):1053-60. https://doi.org/10.1016/j.sjbs.2018.08.006.

Ashraf M, Ahmad S. Influence of sodium chloride on ion accumulation, yield components and fibre characteristics in salt-tolerant and salt-sensitive lines 
of cotton (Gossypium hirsutum L.). Field Crop Res. 2000;66(2):115-27. https:// doi.org/10.3923/jbs.2003.699.710.

Assaha DV, Ueda A, Saneoka $\mathrm{H}$, et al. The role of $\mathrm{Na}^{+}$and $\mathrm{K}^{+}$transporters in salt stress adaptation in glycophytes. Front Physiol. 2017;8:509. https://doi.org/10. 3389/fphys.2017.00509.

Barrs HD, Weatherley PE. A re-examination of the relative turgidity technique for estimating water deficits in leaves. Aust J Biol Sci. 1962;15(3):413-28. https:// doi.org/10.1071/BI9620413.

Borzouei A, Kafi M, Akbari GE, et al. Long term salinity stress in relation to lipid peroxidation, super oxide dismutase activity and proline content of saltsensitive and salt-tolerant wheat cultivars. Chil J Agric Res. 2012;72(4):476. https://doi.org/10.4067/S0718-58392012000400003.

Brugnoli E, Lauteri M. Effects of salinity on stomatal conductance, photosynthetic capacity, and carbon isotope discrimination of salt-tolerant (Gossypium hirsutum L.) and salt-sensitive (Phaseolus vulgaris L.) $C_{3}$ non-halophytes. Plant Physiol. 1991;95(2):628-35. https://doi.org/10.1 104/pp.95.2.628.

Chen X, Min D, Yasir TA, et al. Evaluation of 14 morphological, yield-related and physiological traits as indicators of drought tolerance in Chinese winter bread wheat revealed by analysis of the membership function value of drought tolerance (MFVD). Field Crop Res. 2012;137:195-201. https://doi.org/ 10.1016/j.fcr.2012.09.008

Chen Z, Newman I, Zhou M, et al. Screening plants for salt tolerance by measuring $\mathrm{K}^{+}$flux: a case study for barley. Plant Cell Environ. 2005;28(10): 1230-46. https://doi.org/10.1111/j.1365-3040.2005.01364.x.

Chiconato DA, Junior GD, dos Santos DM, et al. Adaptation of sugarcane plants to saline soil. Environ Exp Bot. 2019;162:201-11. https://doi.org/10.1016/j. envexpbot.2019.02.021.

Chunthaburee S, Dongsansuk A, Sanitchon J, et al. Physiological and biochemical parameters for evaluation and clustering of rice cultivars differing in salt tolerance at seedling stage. Saudi J Biol Sci. 2015;23(4):467-77. https://doi. org/10.1016/j.sjbs.2015.05.013

Ding T, Yang Z, Wei X, et al. Evaluation of salt-tolerant germplasm and screening of the salt-tolerance traits of sweet sorghum in the germination stage. Funct Plant Biol. 2018;45(10):1073-81. https://doi.org/10.1016/j.fcr.2012.09.008.

Elkelish AA, Soliman MH, Alhaithloul HA, et al. Selenium protects wheat seedlings against salt stress-mediated oxidative damage by up-regulating antioxidants and osmolytes metabolism. Plant Physiol Biochem. 2019;137:144-53. https:// doi.org/10.1016/j.plaphy.2019.02.004.

Faroog M, Hussain M, Wakeel A, et al. Salt stress in maize: effects, resistance mechanisms, and management. A review. Agron Sustain Dev. 2015;35(2): 461-81. https://doi.org/10.1007/s13593-015-0287-0.

Gao Y, Lu Y, Wu M, et al. Ability to remove $\mathrm{Na}^{+}$and retain $\mathrm{K}^{+}$correlates with salt tolerance in two maize inbred lines seedlings. Front Plant Sci. 2016;7:1716. https://doi.org/10.3389/fpls.2016.01716.

Garriga M, Muñoz CA, Caligari PD, et al. Effect of salt stress on genotypes of commercial (Fragaria $x$ ananassa) and Chilean strawberry (F. chiloensis). Sci Hortic. 2015;195:37-47. https://doi.org/10.1016/j.scienta.2015.08.036.

Gill SS, Tuteja N. Reactive oxygen species and antioxidant machinery in abiotic stress tolerance in crop plants. Plant Physiol Biochem. 2010;48(12):909-30. https://doi.org/10.1016/.jplaphy.2010.08.016

Gong B, Wen D, VandenLangenberg K, et al. Comparative effects of $\mathrm{NaCl}$ and $\mathrm{NaHCO}_{3}$ stress on photosynthetic parameters, nutrient metabolism, and the antioxidant system in tomato leaves. Sci Hortic. 2013;157:1-2. https://doi.org/ 10.1016/j.scienta.2013.03.032.

Haider MS, Jogaiah S, Pervaiz T, et al. Physiological and transcriptional variations inducing complex adaptive mechanisms in grapevine by salt stress. Environ Exp Bot. 2019;162:455-67. https://doi.org/10.1016/j.envexpbot.2019.03.022.

Hassanvand F, Nejad AR, Fanourakis D. Morphological and physiological components mediating the silicon-induced enhancement of geranium essential oil yield under saline conditions. Ind Crop Prod. 2019;134:19-25. https://doi.org/10.1016/jindcrop.2019.03.049.

He T. Cramer GR. Abscisic acid concentrations are correlated with leaf area reductions in two salt-stressed rapid-cycling Brassica species. Plant Soil. 1996; 179(1):25-33. https://doi.org/10.1007/BF00011639.

Hessini K, Issaoui K, Ferchichi S, et al. Interactive effects of salinity and nitrogen forms on plant growth, photosynthesis and osmotic adjustment in maize. Plant Physiol Biochem. 2019;139:171-8. https://doi.org/10.1016/j.plaphy.2019. 03.005 .

Higbie SM, Wang F, Stewart JM, et al. Physiological response to salt ( $\mathrm{NaCl}$ ) stress in selected cultivated tetraploid cottons. Int J Agron. 2010. https://doi.org/10 1155/2010/643475.
Ismail AM, Horie T. Genomics, physiology, and molecular breeding approaches for improving salt tolerance. Annu Rev Plant Biol. 2017;68:405-34. https://doi. org/10.1146/annurev-arplant-042916-040936.

Kakar N, Jumaa SH, Redoña ED, et al. Evaluating rice for salinity using pot-culture provides a systematic tolerance assessment at the seedling stage. Rice. 2019; 12(1):57. https://doi.org/10.1186/s12284-019-0317-7.

Kawakami EM, Oosterhuis DM, Snider JL. Nitrogen assimilation and growth of cotton seedlings under $\mathrm{NaCl}$ salinity and in response to urea application with NBPT and DCD. J Agron Crop Sci. 2013;199(2):106-17. https://doi.org/10. 1111/jac.12002.

Kumar K, Kumar M, Kim SR, et al. Insights into genomics of salt stress response in rice. Rice. 2013;6(1):1-15. https://doi.org/10.1186/1939-8433-6-27.

Leidi EO, Saiz JF. Is salinity tolerance related to $\mathrm{Na}$ accumulation in upland cotton (Gossypium hirsutum) seedlings? Plant Soil. 1997;190(1):67-75. https://doi.org/ 10.1023/A:1004214825946.

Li J, Pu L, Han M, et al. Soil salinization research in China: advances and prospects. J Geogr Sci. 2014;24(5):943-60. https://doi.org/10.1007/s1 1442-014-1130-2.

Liu Q, Liu R, Ma Y, et al. Physiological and molecular evidence for $\mathrm{Na}^{+}$and $\mathrm{Cl}^{-}$ exclusion in the roots of two Suaeda salsa populations. Aquat Bot. 2018;146: 1-7. https://doi.org/10.1016/j.aquabot.2018.01.001.

Liu Y, Wang X, Zhang G, et al. Research on evaluation method of salt tolerance at seedling stage in cotton. Modern Agric Sci Technol. 2011;7:11,16 (in Chinese with English abstract).

Long WH, Pu HM, Zhang JF, et al. Screening of Brassica napus for salinity tolerance at germination stage. Chin J Oil Crop Sci. 2013;35:271-5 (in Chinese with English abstract).

Meloni DA, Oliva MA, Ruiz HA, et al. Contribution of proline and inorganic solutes to osmotic adjustment in cotton under salt stress. J Plant Nutr. 2001;24(3): 599-612. https://doi.org/10.1081/PLN-100104983.

Munns R, James RA, Gilliham M, et al. Tissue tolerance: an essential but elusive trait for salt-tolerant crops. Funct Plant Biol. 2016;43(12):1103-13. https://doi. org/10.1071/FP16187.

Munns R, Tester M. Mechanisms of salinity tolerance. Annu Rev Plant Biol. 2008; 59:651-81. https://doi.org/10.1146/annurev.arplant.59.032607.092911.

Nounjan N, Theerakulpisut P. Effects of exogenous proline and trehalose on physiological responses in rice seedlings during salt-stress and after recovery. Plant Soil Environ. 2012;58(7):309-15. https://doi.org/10.17221/762/2011-PSE.

Penella C, Nebauer SG, Quinones A, et al. Some rootstocks improve pepper tolerance to mild salinity through ionic regulation. Plant Sci. 2015;230:12-22. https://doi.org/10.1016/j.plantsci.2014.10.007.

Peng Z, He S, Gong W, et al. Comprehensive analysis of differentially expressed genes and transcriptional regulation induced by salt stress in two contrasting cotton genotypes. BMC Genomics. 2014;15(1):760. https://doi.org/10.1186/ 1471-2164-15-760.

Peng Z, He S, Gong W, et al. Integration of proteomic and transcriptomic profiles reveals multiple levels of genetic regulation of salt tolerance in cotton. BMC Plant Biol. 2018;18(1):128. https://doi.org/10.1186/s12870-018-1350-1.

Rahneshan Z, Nasibi F, Moghadam AA. Effects of salinity stress on some growth, physiological, biochemical parameters and nutrients in two pistachio (Pistacia vera L.) rootstocks. J Plant Interact. 2018;13(1):73-82. https://doi.org/10.1080/ 17429145.2018 .1424355

Sade N, del Mar R-WM, Umnajkitikorn K, et al. Stress-induced senescence and plant tolerance to abiotic stress. J Exp Bot. 2017;69(4):845-53. https://doi.org/ 10.1093/jxb/erx235

Sánchez-Rodríguez E, Rubio-Wilhelmi M, Cervilla LM, et al. Genotypic differences in some physiological parameters symptomatic for oxidative stress under moderate drought in tomato plants. Plant Sci. 2010;178(1):30-40. https://doi. org/10.1016/j.plantsci.2009.10.001.

Sarabi B, Bolandnazar S, Ghaderi N, et al. Genotypic differences in physiological and biochemical responses to salinity stress in melon (Cucumis melo L.) plants: prospects for selection of salt tolerant landraces. Plant Physiol Biochem. 2017;119:294-311. https://doi.org/10.1016/j.plaphy.2017.09.006.

Sarabi B, Fresneau C, Ghaderi N, et al. Stomatal and non-stomatal limitations are responsible in down-regulation of photosynthesis in melon plants grown under the saline condition: application of carbon isotope discrimination as a reliable proxy. Plant Physiol Biochem. 2019;141:1-9. https://doi.org/10.1016/j. plaphy.2019.05.010.

Sehar Z, Masood A, Khan NA. Nitric oxide reverses glucose-mediated photosynthetic repression in wheat (Triticum aestivum L.) under salt stress. Environ Exp Bot. 2019;161:277-89. https://doi.org/10.1016/j.envexpbot.2019. 01.010. 
Shi G, Cai Q, Liu C, et al. Silicon alleviates cadmium toxicity in peanut plants in relation to cadmium distribution and stimulation of antioxidative enzymes. Plant Growth Regul. 2010;61(1):45-52. https://doi.org/10.1007/s10725-0109447-z.

Sinclair TR, Ludlow MM. Influence of soil water supply on the plant water balance of four tropical grain legumes. Funct Plant Biol. 1986;13(3):329-41. https://doi.org/10.1071/PP9860329.

Singh DP, Sarkar RK. Distinction and characterisation of salinity tolerant and sensitive rice cultivars as probed by the chlorophyll fluorescence characteristics and growth parameters. Funct Plant Biol. 2014;41(7):727-36. https://doi.org/10.1071/FP13229.

Sorkheh K, Shiran B, Rouhi V, et al. Salt stress induction of some key antioxidant enzymes and metabolites in eight Iranian wild almond species. Acta Physiol Plant. 2012;34(1):203-13. https://doi.org/10.1007/s11738-011-0819-4.

Suriya-arunroj D, Supapoj $N$, Toojinda T, et al. Relative leaf water content as an efficient method for evaluating rice cultivars for tolerance to salt stress. ScienceAsia. 2004;30:411-5. https://doi.org/10.2306/scienceasia1513-1874. 2004.30.411.

Tester M, Davenport R. $\mathrm{Na}^{+}$tolerance and $\mathrm{Na}^{+}$transport in higher plants. Ann Bot. 2003;91(5):503-27. https://doi.org/10.1093/aob/mcg058.

Wang N, Wang X, Shi J, et al. Mepiquat chloride-priming induced salt tolerance during seed germination of cotton (Gossypium hirsutum L.) through regulating water transport and $\mathrm{K}^{+} / \mathrm{Na}^{+}$homeostasis. Environ Exp Bot. 2019; 159:168-78. https://doi.org/10.1016/j.envexpbot.2018.12.024.

Wang W, Vinocur B, Altman A. Plant responses to drought, salinity and extreme temperatures: towards genetic engineering for stress tolerance. Planta. 2003; 218(1):1-4.

Wang H, Takano T, Liu SK. Screening and evaluation of saline-alkaline tolerant germplasm of rice (Oryza sativa L.) in soda saline-alkali soil. Agronomy. 2018; 8(10):205. https://doi.org/10.3390/agronomy8100205.

Wu H, Guo J, Wang C, et al. An effective screening method and a reliable screening trait for salt tolerance of Brassica napus at the germination stage. Front Plant Sci. 2019;10:530. https://doi.org/10.3389/fpls.2019.00530.

Ye W, Liu J. Identification technology and application of salt tolerance of cotton germplasm resources. China Cotton. 1998;25(9):34 (in Chinese).

Zeng L, Shannon MC, Grieve CM. Evaluation of salt tolerance in rice genotypes by multiple agronomic parameters. Euphytica. 2002;127(2):235-45. https:// doi.org/10.1023/A:1020262932277.

Zhang L, Ma H, Chen T, et al. Morphological and physiological responses of cotton (Gossypium hirsutum L.) plants to salinity. PLoS One. 2014;9(11): e112807. https://doi.org/10.1371/journal.pone.0112807.

\section{Ready to submit your research? Choose BMC and benefit from:}

- fast, convenient online submission

- thorough peer review by experienced researchers in your field

- rapid publication on acceptance

- support for research data, including large and complex data types

- gold Open Access which fosters wider collaboration and increased citations

- maximum visibility for your research: over $100 \mathrm{M}$ website views per year

At BMC, research is always in progress.

Learn more biomedcentral.com/submissions 